\title{
Seguindo a constituição da Joalheria contemporânea
}

\author{
Siguiendo la creación de la joyería contemporánea
}

Following the constitution of the Contemporary Jewelery

\author{
Ana Neuza Botelho Videla'
}

Palavras chave:

Joalheria

contemporânea

Teoria do Ator-Rede

Arte

\section{Resumo:}

A proposta deste estudo visou apresentar o segmento profissional da joalheria, tendo por objetivo identificar em quais circunstâncias a joalheria é considerada arte, por ser uma categoria orientada para a produção de trabalhos mais experimentais, os quais podem ter a intenção de problematizar a ornamentação corporal ou a linguagem da joalheria. Do ponto de vista metodológico, distinguir as características dos produtos gerados por artistas joalheiros implicou no acompanhamento das práticas de produção, comercialização, eventos de divulgação e lançamentos de projetos. A construção teórica da pesquisa objetivou abarcar o ponto de vista do sujeito e seu contexto. Neste sentido, a obra de Bruno Latour contribuiu para se pensar a constituição de uma categoria artística. Como resultados, observamos que os joalheiros, por se situarem entre dois campos de práticas, parecem se encontrar em um espaço liminar. De um lado, afirmam que o que os diferenciam das outras formas de produzir joalheria é a exploração ou experimentação do objeto associado ao corpo. De outro, tem-se o conhecimento especializado da joalheria, o qual faz a mediação das influências externas. 


\begin{abstract}
Resumen:
Este estudio se presenta en el segmento profesional de la joyería, con el objetivo de identificar las circunstancias que coloca la joyería es arte, como una categoría específica para una producción de obras más experimentales, que puede tener la intención de problematizar una ornamentación corporal o la lenguaje de joyería. Desde un punto de vista metodológico, para distinguir las características de los productos generados por los artistas joyeros, resultó en seguir las prácticas de producción, marketing, eventos de difusión y lanzamiento de proyectos. La construcción teórica de la investigación tiene como objetivo abarcar punto de vista del sujeto y su contexto. En este sentido, la obra de Bruno Latour contribuye a pensar en una constitución de una categoría artística. Como resultado, se observó que los joyeros, ya que se encuentran entre dos campos prácticas parecen encontrar en un espacio liminal. Por un lado, afirman que se diferencian de otras formas de producción de la joyería por una exploración o experimentación del objeto asociado con el cuerpo. Por otro lado, se tiene la experiencia de la joyería, que media las influencias externas.
\end{abstract}

\section{Palabras clave:}

Joyería contemporánea

Actor-Red Teoría

Art

\section{Keywords: \\ Contemporany jewelry \\ Actor-Network Theory}

Art

\section{Abstract:}

The purpose of this study is to present in the professional segment of jewelry, in order to identify in some circumstances the jewelry is a conceptual art, because it is a category oriented towards a production of more experimental works, which may have an intention to problematize a body ornamentation Or A language of jewelry. From the methodological point of view, distinguish as characteristics of products generated by implied jewelers artists not following the practices of production, marketing, promotion events and project launches. The theoretical construction of research aims to encompass the subject's point of view and its context. In this sense, a work by Bruno Latour helps to think of a constitution of an artistic category. As a result, we find that the jewelers, as they lie between two practice fields, seem to be in an opening space. On the one hand, statement that what differ from other forms of jewelry production is an exploration or experimentation of the object associated with the body. On the other hand, it has the specialized knowledge of jewelry, which mediates external influences. 


\section{Seguindo a constituição da Joalheria contemporânea}

\section{Introdução}

Apresenta-se, neste artigo, parte da pesquisa realizada para a tese de doutorado Joalheria, arte ou design? (VIDELA, 2016). A joalheria que aqui se analisa é a ocupação profissional desenvolvida nos dias atuais, na qual pode prevalecer uma compreensão mais artística ou mais comercial da atividade a depender do contexto ou da segmentação abordada. Algumas dessas posições estão mais próximas do design, enquanto outras mais próximas da arte. Para isso, retoma-se a discussão das várias formas de atuação profissional, nas quais se apresentam tanto o sujeito que produz artesanalmente, quanto as produções industriais, em contraponto com os que estão problematizando a joia como adorno corporal, e que estão, de certa maneira, levando o problema da linguagem artística ao seu extremo.

Como a atuação nesse campo, assim como em tantas outras atividades profissionais, pode ocorrer de distintas maneiras, sob diferentes perspectivas, buscou-se apresentar as categorias mais emblemáticas da joalheria, para em seguida determo-nos na joalheria contemporânea, compreendida como uma linguagem artística.

Portanto, a proposta foi identificar, entre os produtores que se posicionam como produtores de artefatos com expressão artística, os processos que condicionam suas atuações nessa atividade profissional. Pois, de acordo com a argumento deste estudo, pode-se evidenciar nos diferentes desempenhos, uma análise das estruturas e processos que condicionam as atuações dos sujeitos.
Em termos metodológicos, foi adotada a teoria do ator-rede - TAR (LATOUR, 1994, 2004a, 2012), cujo método consiste na observação participante e descrição, aos moldes da etnografia.

A pesquisa inicialmente contaria com informantes apenas do Brasil, porém, ao longo do processo do doutorado, surgiu a oportunidade de fazer o estágio doutoral no departamento de Antropologia da UAM, na Cidade do México. Quase que simultaneamente tomei conhecimento, através de um artigo originário de um Fórum de joalheria contemporânea", da existência de um coletivo"' de artistas joalheiros também na Cidade do México, daí oportunizou-se a ideia de, a partir dessa informação, dar continuidade ao trabalho de campo com joalheiros contemporâneos estrangeiros.

\section{Facetas da joalheria}

A atividade joalheira, na perspectiva dos produtores, conta com especificidades que a faz formar especialistas, oferecendo uma direção contrária da tendência que outros setores econômicos enfrentam da flexibilização do trabalho (CANCLINI, 2012). Em vez disso, observa-se na joalheria uma atividade profissional de muita tradição, identificável mais fortemente em algumas regiões. Com o intuito de ilustrar em que consiste a especificidade da formação joaIheira, passa-se ao relato da joalheira Tissa Berwanger e de sua experiência na Alemanha, país com vasto lastro na área. Tissa, após um primeiro contato com as técnicas de joalheria na Escola de Ourivesaria do SENAI-RJ, optou por complementar sua formação em joalheria na Zeichenakademie Hanau, Alemanha, escola conhecidas pela excelência na formação técnica. A sua escolha por essa escola foi motivada pela orientação que a escola possui em formar ourives como produtor e criador de joia. Tissa enfatiza que não se trata de uma escola de design de joias e ainda esclarece que, 
"há uma diferença entre design de joias e gestaltung de joias, o design é orientado para a indústria, enquanto a gestaltung é focada na configuração da joia, na joalheria de autoral" (Entrevistada). Segundo Tissa, a cidade de Hanau, na Alemanha, conta com várias instituições que reforçam a importância da joalheria para a comunidade local. Além disso, contam com tecnologia para a produção dos materiais utilizados na fabricação de joias, que não encontramos no Brasil. Para isso, é fundamental contar com equipamentos como laminadores grandes, que permitem a elaboração de chapas de espessura calibrada e de grande dimensão. Ou seja, contam com facilidades que auxiliam no desenvolvimento profissional.

Na cidade de Hanau, não só tem a escola, eles tem o museu que é o Goldschmeidhaus, todas as exposições que passam por Munique, elas vão parar em Goldschmeidhaus. Eles têm várias empresas de metal, eles têm a Heraeus que vende 'os metais', então os alunos encomendam... os alunos que fazem objetos, tem uma turma só de objetos de prata, eles encomendam uma chapa grande de prata, lisinha, da espessura que eles queiram. Pra fazer o desenho é muito fácil, virava o metal aqui, virava o metal ali, você fazia um objeto porque você tem essa possibilidade de ter chapas grandes, muda a sua forma de pensar no projeto. $E$ eram muitos incentivos, no projeto final, a gente pedia o metal e podia devolver o resto. Então a gente só pagava aquilo que se usava. Tudo, soldas, metais, todos perfeitos e maravilhosos. Tinha uma empresa de ferramentas, que vende pra Alemanha inteira, na própria cidade, então era muito fácil você comprar e ter o material. E se no meio da aula você via que tinha que ter uma broca, na hora da pausa você corria com a bicicleta e comprava a broca e voltava. Então dava pra desenvolver.

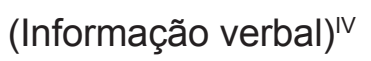

Embora o exemplo da formação alemã esteja muito distante do que ocorre na realidade brasileira, a intenção de mostrar uma formação de excelência é poder identificar a construção de um especialista, cujo início ocorre desde a seleção dos alunos, que é constituída por provas, uma de desenho, outra que avalia a habilidade em construções com papel, ou seja, a escolha dos alunos para a escola técnica de joalheria está condicionada a que eles possuam habilidades manuais. Uma vez identificado os candidatos possuidores dessas habilidades, os alunos serão introduzidos aos saberes ${ }^{\vee}$ relacionados à atividade e treinamento em técnicas finas e precisas, em um curso com duração de três anos e meio e com 35 horas de carga horária semanal. Para além dessa formação, os joalheiros contam ainda com facilidades para a condução da profissão, desde o acesso de toda cadeia produtiva, de materiais, metais, ligas especiais e ferramentas de qualidade ${ }^{\mathrm{VI}}$, a eventos relacionados ao segmento, espaços expositivos e de comercialização. Esse contexto favorece o desenvolvimento dos profissionais, uma vez que possuem acesso às tecnologias que facilitam a materialização dos projetos, além de contarem com a permanente circulação do trabalho de outros produtores, estimulando a reflexão do universo no qual estão envolvidos.

Feita essas considerações, passa-se para uma concisa apresentação da joalheria. A atividade que aqui discutiremos é a composição do segmento da joalheria e sua relação de profissionalização hoje, no qual pode prevalecer uma compreensão mais artística ou mais comercial da atividade a depender do contexto ou da segmentação abordada.

\subsection{Joalheria de Autor}

Para Liesbeth den Besten (2011), há uma série de categorias que compõem a Joalheria, tais como: joalheria contemporânea, 
joalheria de estúdio, arte joalheria, joalheria de pesquisa, design joalheria e joalheria de autor. Alguns desses termos têm origem específica em um país, como é o caso da "joalheria de autor", derivação do "Cinema de Autor", que surgiu na França, na década de 1950, através das ideias de François Truffaut e André Bazin. Em seguida, esse termo se expandiu para uma experiência nova com a Joalheria, também mais relacionada à arte, até ganhar outras regiões.

Para Ramón Puig Cuyás ${ }^{V I I}$ (ROJAS, 2016), "La joya de autor es un término confuso que solo nos indica la voluntad de autoría, pero no nos da información de si es un producto artístico, de artesanía, de diseño o de joyería convencional"VIII Portanto, joalheria de autor não é uma denominação adotada atualmente pelos informantes para se referirem à joalheria com expressão artística, pois identificam no termo uma carência de rigor e referência a um período. Contudo, esse termo foi muito utilizado pelos joalheiros brasileiros nas décadas de 1980 e 1990. De acordo com a informante Elizabeth Franco, joaIheria de autor era a designação adotada pelos produtores que buscavam uma criação própria, tanto na forma como no material, em oposição às joias comerciais. Entretanto, o termo após esse período, foi paulatinamente caindo em desuso.

\subsection{Alta Joalheria}

A categoria da alta joalheria possui o propósito de produzir peças de luxo. Isso significa que para fabricar peças dessa categoria enfatiza-se, sobretudo, dois elementos: matéria-prima rara e mão-de-obra altamente qualificada e extremamente habilidosa. As matérias-primas utilizadas nestas peças são, sobretudo, as ligas, que é a combinação de dois ou mais metais, e as gemas $^{\mathrm{IX}}$ com características naturais especiais. As gemas precisam possuir vários aspectos para alcançar valor no mercado joalheiro, tais como; elevado teor de pureza, intensidade na cor (quando se trata de gema corada), não apresentar clivagem, nem incrustação. A lapidação é um beneficiamento pelo qual a gema passa antes da montagem na joia, cujo objetivo é realçar a beleza dos minerais, amplificando suas propriedades físicas, como o brilho (reflexão), o fogo (dispersão), o jogo de cores das gemas, entre outros aspectos, de acordo com a estrutura cristalina de cada material. Com relação à mão-de-obra, o outro aspecto destacado da produção da alta joalheria, implica em uma formação longa e, por isso, cara, na qual o pretendente deve ser iniciado ainda jovem, por volta dos 15 ou 16 anos, pois quanto mais jovem iniciar no ofício, mais facilidade terá em incorporar habilidades mais finas ${ }^{x}$. A produção de uma peça de alta joalheria exige um alto grau de perfeição, evidentemente que outras características são importantes, como o design e as inovações tecnológicas, no entanto, os dois itens destacados são os mais emblemáticos para essa categoria. Como é exigido um alto grau de perfeição nos produtos desta categoria, a produção não pode prescindir da maestria do artesão, combinado com matérias-primas especiais e raras. Esse aspecto acaba por não permitir muita escala, pois a ênfase recai na qualidade da execução. Virgílio Bahde, um dos nossos informantes, compara a fabricação de peças de alta joalheria com a fabricação de produtos de marcas de luxo. Assim, ele diz, "é um sistema de indústria, mas uma indústria que passa por um processo artesanal. É como a fabricação de bolsas da Hermès, que conta com o melhor couro, [...] é industrial? É, mas é feito com os padrões do artífice. Tem que ter um artífice ali, que conhece muito, a vida dele é aquilo [...]".

\subsection{Joalheria Industrial ou de Estúdio}

Ajoalheria industrial, por sua vez, se distingue das outras categorias que compõem o universo da joalheria por adotar as práticas do design com intuito de obter escala. Neste aspecto, a contribuição do design é no sentido de desenvolver projetos que permitam agilizar a produção. Desse 
modo, ao otimizar os recursos a fim de atingir escala, essa categoria opera a diferença mais marcante com a alta joalheria. Aqui a tecnologia tem um papel relevante na obtenção de um produto de qualidade, tanto no acabamento, quanto no design, tendo em vista proporcionar o desenvolvimento de peças inovadoras. Assim, a indústria faz uso de várias tecnologias, como a prototipagem rápida, e algumas ferramentas de modelagem que possibilitam a criação de peças que não poderiam ser executadas na bancada do ourives. A solda a laser é outra tecnologia que permite soldar distintos materiais, que não poderiam ser unidos através dos processos tradicionais da ourivesaria. Ou seja, ao alterar o processo de fabricação da joia, o uso da tecnologia possibilita uma nova configuração da joia e, com isso, mantêm-se a competitividade do negócio.

A trajetória da informante Lívia Canuto, designer de joia, ilustra bem a distinção das categorias, pois no período da pesquisa Lívia operava a mudança de designer de joias de atelier para uma produção industrial. Lívia iniciou sua formação no curso de escultura das Belas Artes, UFRJ e, pouco tempo depois, ingressou no curso de desenho industrial da UniverCidade, também no Rio de Janeiro. Durante um período, chegou a frequentar os dois cursos, até fazer a opção pelo design. Para Lívia, designer de formação, o campo da joalheria pode ser compreendido da forma relatada a seguir.

Eu vejo a alta joalheria, que é Tifany, Cartier, [...] vejo uma joalheria mais industrial, [...] mais ligada ao design. Para mim o Antonio Bernardo é industrial, tem fábrica, tem muitas lojas, tem produção, mas tem a preocupação de designer. Tem o industrial H.Stern, que cada vez mais tem uma preocupação com o design. Uns são mais bem sucedidos que outros em relação a isso, mas é industrial. Vejo pequenos produtores, designers no mercado, com seus ateliês, com suas oficinas, com suas produções mais reduzidas. Que também estão comercializando. E tem os artistas joalheiros, que infelizmente eu não vejo mercado para eles se mostrarem. Não vejo galerias que estejam abertas para receber esses joalheiros. Não vejo exposições aqui. Mas eu sei que tem uma minoria que tem outra proposta dentro do ramo todo da joia. (Entrevistada) ${ }^{\mathrm{XI}}$.

Lívia, ao ser indagada sobre a forma em que atua no campo da joalheria, diz que se vê "como um pequeno atelier, uma pequena oficina, como designer de joias, porque tenho preocupações que fazem parte do design, da comercialização, da estética, da funcionalidade." Mas em breve Lívia vai abrir uma loja no Shopping da Gávea, local que se destaca na área da joalheria, pois conta com várias marcas do segmento. Assim, ela diz que vai "deixar de ter a cara de atelier, pra ter um negócio mais industrial, mas sempre com a preocupação do design". A distinção que Lívia faz entre a joalheria de atelier para a joalheria industrial é a escala.

Portanto, a depender do nicho que a empresa escolhe atuar, é possível agilizar e otimizar boa parte da produção, no sentido de eliminar ao máximo as etapas artesanais de montagem das peças e os processos de acabamentos manuais, os quais passam da bancada do ourives para procedimentos automatizados da produção. A fabricação continua a ter uma predominância de materiais nobres, mas a joalheria industrial pode adotar combinações com outros materiais, como madeira, couro, esmaltes, aço e titânio, etc. Para essa categoria de joalheria, tanto o design, como o processo produtivo visam agilizar a produção.

Por conseguinte, pode-se definir a joalheria de estúdio como sendo executada por produtores individuais em seus próprios ateliês, em que podem contar 
com um ou dois assistentes, mas o que vale destacar nessa forma de produção é o controle que o produtor tem de todas as etapas de fabricação da peça, da ideia à comercialização, cabendo aos assistentes as etapas de preparação do metal ou materiais a serem adotados na produção, assim como do acabamento das peças.

\subsection{Joalheria Contemporânea ou Arte Joalheria}

Joalheria Contemporânea ou Arte Joalheria são denominações adotadas de maneira intercambiável, sem distinção, assim, os dois termos são usados para designar a categoria da joalheria pautada pela arte. Historicamente, este segmento da joalheria surgiu na década de 1960, período de plena efervescência no campo da arte, tendo como um dos seus principais pressupostos problematizar a própria linguagem da joalheria, tais como: o luxo, a preciosidade, os materiais, as técnicas, a tipologia adotada e a ornamentação. Os primeiros joalheiros a participarem do segmento artístico da joalheria criaram peças em que levantavam questões sobre preciosidade, ornamentação e usabilidade, desafiando e explorando a tradição do campo para contestá-la. Pode-se, inclusive, pensar o questionamento da própria linguagem da joalheria como o indicativo de um amadurecimento do campo, pois algo muito próximo havia acontecido com a arte contemporânea através do seu processo de diferenciação da arte moderna, no sentido em que problematizou a própria linguagem de representação do mundo e do seu modo de fazer artístico.

De acordo com Archer (2001), as mudanças que ocorreram na arte da Europa e Estados Unidos, sobretudo, a partir da pop art, mas também com o surgimento do minimalismo e da arte conceitual, deflagrou-se uma modificação da relação entre arte e vida cotidiana. Nesse sentindo, os novos movimentos procuravam aproximar a arte da vida cotidiana. Pode-se observar, nos trabalhos desse período, que muitas obras da pop art faziam referências ao comportamento, atitudes e estilo de vida da América contemporânea. A concentração era nos lugares-comuns ou nas banalidades da existência. De modo que o significado do trabalho podia não estar mais contido na própria obra, mas, antes, encontrar-se associado ao contexto que o artista queria discutir. Esse contexto podia ser tanto o movimento artístico anterior, que no caso da pop art era o expressionismo abstrato, quanto questões relacionadas ao consumo cotidiano. As obras deixaram de ser avaliadas e pensadas, prioritariamente, em termos estéticos; outros aspectos passaram a ser ressaltados.

Um dos rompimentos mais significativos, desse período, foi em relação à narrativa modernista da história da arte. Essa mudança histórica da produção da arte foi conhecida como o "fim da arte", tese defendida tanto por Hans Belting (2006), como por Arthur Danto (2006), cujo sentido "tinha mais a ver com a maneira como a história da arte tinha sido concebida enquanto uma sequência de fases de uma narrativa em desdobramento" (DANTO, 2013, p. 3). Dito de outra maneira, trata-se do fim da narrativa que teve início no renascimento, em que se levava em conta um encadeamento dos movimentos pensados em termos de uma linha evolutiva. Esse modelo de narrativa não mais servia para compreender as novas proposições de arte que surgiram a partir da década de 60. Para o entendimento da arte contemporânea precisava-se de uma narrativa de outra ordem, pois as exposições dos acontecimentos artísticos passaram a não ser narrados de forma encadeada, na qual um movimento sucede outro. Desse modo, foi identificado um fim para a narrativa da história da arte, mas obviamente não para as obras de arte, o assunto transmitido por essa narrativa. 
Entretanto, o maior desafio foi o reconhecimento de que o significado de uma obra não estava necessariamente contido nela, mas podia emergir do contexto em que se encontrava, o qual podia ser social, político ou formal. A arte contemporânea precisava ter significado e ter sua apresentação coadunada com esse significado; as questões estéticas não eram mais a problemática norteadora de uma obra.

Com relação à arte joalheria, observa-se, neste mesmo período, os trabalhos de alguns artistas joalheiros que discutem os aspectos constitutivos do seu campo, trazendo conceitos a partir de seus envolvimentos com a linguagem da joalheria, tais como: o corpo, as questões sociais e políticas que os cercavam, o luxo, a ornamentação. Assim, foi a partir da década de 1960 que os joalheiros começaram a questionar seu próprio campo de ação. A primeira geração de joalheiros europeus, que inclui os suíços Otto Künzli (1948) e Bernhard Schobinger (1946), o holandês Gijs Bakker (1942), a inglesa Caroline Broadhead (1950), sentiam-se desconfortáveis frente às convenções do mundo da joalheria e suas tradicionais conotações de luxo e riqueza (DEN BESTEN, 2011). Para Damian Skinner (2013), crítico de arte contemporânea, Künzli é o mais perfeito exemplo da natureza crítica e conceitual do campo.

By this I mean the way contemporary jewelry objects and practices are intended to actively grapple with the conditions and circumstances in which contemporary jewelry takes place. In general, contemporary jewelers work in a critical or conscious relationship to the history of the practice and to the wider field of jewelry and adornment (SKINNER, 2013, p. 1).

Desse modo, pode-se identificar que essa categoria busca problematizar os elementos que constituem a linguagem da joalheria, se contrapondo à joalheria hegemônica do período. Portanto, joalheria contemporânea é uma categoria muito recente, cuja disposição propriamente estética, se opera através da experiência com a arte que a subsome na função corporal. Ou seja, a arte joalheria toma por base os pressupostos do campo da arte, por um lado, e, por outro, a arte a concebe associada à função corporal. Sendo precisamente essa característica, a função, que para o campo da arte afasta a possibilidade da joalheria ser considerada uma atividade artística.

A fim de ilustrar o surgimento da categoria da joalheria contemporânea, cito o depoimento de Rudolf Ruthner ${ }^{\mathrm{X} \|}$, para quem essa categoria surgiu para se contrapor à alta joalheria e aos altos custos envolvidos nos materiais empregados nas peças. Rudolf explica que na década de 1960 os produtores mais jovens, formados pelas melhores escolas europeias, dominavam com maestria a técnica da ourivesaria.

[...], a joia contemporânea começou nos anos 70, não? Eu conheci pessoas que começaram com isso. Meu amigo fez a primeira exposição quando abriu a Electrum Gallery, em Londres, ele foi o primeiro. Como aconteceu? Veio da ourivesaria tradicional, não da ourivesaria, mas de certa forma da ourivesaria tradicional, cada um, esses artesãos, procuraram uma linguagem própria, cada um desenvolveu um determinado estilo e se afastaram da alta joalheria. Eles foram contra essa forma de fazer joalheria porque era muito caro, as pedras eram caras e coisas assim. Mas os primeiros contemporâneos em 1960 e 1970, eles usaram materiais tradicionais e não tradicionais cada um, Hermann Jünger, meu amigo Fritz Maierhofer, de Viena, criaram uma coisa, quando você via a peça sabia de quem era e eles tinham clientela, eles vendiam. (Entrevistado) ${ }^{\mathrm{XIII}}$. 
De acordo com relato acima, a joalheria contemporânea foi uma saída que os produtores encontraram para enfrentar os altos custos envolvidos na fabricação de peças de luxo. Para se diferenciarem da alta joalheria, passaram a desenvolver um trabalho de cunho mais pessoal, cuja proposta foi misturar materiais nobres com materiais alternativos.

Os joalheiros que se auto nomeiam artistas joalheiros parecem se encontrar em um espaço à margem das convenções. De um lado, afirmam que o que os diferencia das outras formas de produzir joalheria é a exploração ou experimentação ${ }^{X I V}$ da joia, em que a própria concepção de joaIheria sofreu uma expansão, podendo ser um objeto, um vídeo ou imagem, cujo intuito pode ser problematizar os efeitos de adornar, ou refletir sobre o sentido de tomar emprestado as qualidades aparentes das coisas, ou mesmo questionar a própria linguagem da joalheria, como o luxo, a preciosidade, a ornamentação ou a tipologia. Por outro lado, a distinção que esses produtores ressaltam entre as suas atividades e as outras expressões artísticas é a interação com o corpo. Para defenderem a formulação da joia como objetos de arte argumentam que possuem o mesmo espaço exploratório que a arte. A diferença é ter como suporte o corpo, o qual gera um modo mais direto de experimentar o objeto, tanto através da interação entre os expectadores, como individualmente, tendo o corpo como plataforma de exibição.

A interação do objeto-joia e corpo ou o corpo sendo afetado pelo objeto e vice versa, em que o trabalho muitas vezes se completa no uso, seria a diferença seminal entre a joalheria contemporânea e outros segmentos da arte. De acordo com o depoimentos de Francisca Kweitel ${ }^{\mathrm{XV}}$, muitos trabalhos saem do espaço físico do corpo, defendendo que nem todo resultado da produção de arte joalheria precisa ser portado ao corpo. Para exemplificar, Francisca cita o trabalho de Liesbet Bussche, "Urban Jewellery"xvı, em que o trabalho é um colar de contas, executado com areia e dentro de um canteiro de obra. Outro exemplo a que Francisca recorreu foi o trabalho que Gemma Draper ${ }^{\mathrm{XVII}}$ realizou durante seu período de residência artística em Middlesbrough, na Inglaterra, que consiste em fotografias de sinalização das ruas da cidade, mais especificamente no bairro que morou, onde as ruas tinham nomes como, Rua Pérola, Rua Diamante, Rua Esmeralda, Rua Coral e assim por diante. Para a comunidade local, Gemma explica, a localização se chama de Jewellery Streets. A coincidência de morar nessa localidade a fez realizar uma série de fotos com as sinalizações, pois como ela mesma comentou, era a primeira vez que usava pedras preciosas no seu trabalho de joalheria.

Portanto, mesmo que os trabalhos citados por Francisca escapem do espaço físico do corpo, todos eles fazem referência à linguagem da joalheria, ora usam uma tipologia da joalheria, como o colar, mesmo que em espaços urbanos e em grande escala, ora usam equipamentos ou sinalizações da cidade por adotarem termos recorrentes ou materiais adotados na tradição joalheira, tendo como produto ou resultado final as imagens. De modo que, observa-se que vários trabalhos não necessariamente usam o corpo como suporte, mas fazem referência ao universo da joalheria. Ainda de acordo com Francisca, a aproximação com a arte, ou melhor, dizendo, os que fazem arte a partir da atuação na joalheria, buscam romper com os limites impostos pelas convenções da joalheria.

[...] quizás en algunos trabajos como en las fotos intervenidas que tenía Célio43 en la exposición, ¿son joyería? Son fotos, papeles, plastificadas, puestas en la pared, no se llevan en el cuerpo, ahora las piezas que estaban dentro de la caja de Célio, ¿Son joyería? Tienen pin, se pueden poner de 
alguna forma. Bueno, es un artista, el lo decía, yo soy un creador. El mismo lo decía también que el tenia problemas con sus piezas, porque dentro da joyería eran un poco difíciles de serien llevadas, pesadas, grandes y dentro de la escultura son muy pequeñas. Entonces es como ni una, ni la otra. Ahí es donde los límites empiezan a volver confuso. Y con Gemma me parece que pasa lo mismo, no sé. Cuando te pones a sacar fotos de las calles porque se llaman piedras preciosas 0 porque lo que sea, o cuando se pone a hacer eses dibujos monoprint, grabados, cual es el límite? Entonces, a mi, el simposio sí me importa mucho, me importa que eso sea cada vez más. Sí, es un encuentro de joyeros, pero hasta donde podemos empujar en esos límites. (Entrevista) ${ }^{\mathrm{xVIII}}$.

Outro aspecto muito enunciado, sobretudo pelos integrantes do coletivo "Sin Título"XIx, aponta para a função de comunicação das joias. Nesse sentido, como expressou Fernanda Barba, integrante do coletivo mexicano, "desde luego este tipo de joyería es arte, ya que expresa y tiene el interés de comunicar y hacer sentir", ou ainda, em outro momento da mesma conversa, quando reforça a aproximação entre a joalheria contemporânea e a arte, "desde el momento en el que no es diseño de joyería, sino una pieza que es emocional". Para Cristina Celis, a joalheria contemporânea pode ser definida como, "piezas únicas, con manufactura precisa, impecable que transmiten un significado, un mensaje y vuelcan el interior de quien las creó".

A partir dos depoimentos acima proferidos, pode-se identificar duas formulações usadas na definição da joaIheria contemporânea e do seu espaço de liminaridade (TURNER, 1974), de um lado, observa-se que os enunciados dos joalheiros contemporâneos que passaram por escolas e que fizeram formação neste segmento da joalheria, exploram e experimentam com mais rigor as fronteiras que demarcam o espaço do campo, até ao ponto de alguns produtores se incomodarem em manter a denominação de joaIheiros. Nesse sentido, os relatos de Célio Braga, Gemma ou de Francisca, após alguns trabalhos mais transgressores, como performance, vídeos, fotografias, apontaram para as dúvidas em relação à atividade de atuação, chegando a se questionar se estavam fazendo joalheria. Por trabalho transgressor entendem-se trabalhos em que as fronteiras entre as disciplinas ficam mais difusas. Para Francisca, as classificações apenas facilitam as conversações, mas não fazem sentido, concluindo que "voy ser siempre joyera, porque lo fue de una forma muy intensa y ya está dentro de mi cuerpo. Entonces eso no se va ir más". Do outro lado, nas formulações dos joalheiros autodidatas prevalece a reinterpretação que dão para o trabalho realizado no interstício das diferentes disciplinas. Assim, a diferenciação que os joalheiros fazem entre a joalheria de design e a arte joalheria está relacionada a quem o trabalho está direcionado, se precisa atender às necessidades do usuário ou do artista. A definição mais recorrente da joalheria contemporânea é a de comunicar intenções e inquietações do criador ou conceitos, mesmo que essa comunicação seja para uma audiência pequena. Outro aspecto salientado está relacionado à escala, em geral, identificam a joalheria contemporânea à fabricação de peças únicas. Em suma, como a joalheria contemporânea realizada na América Latina é mais recente, onde não se pode contar com uma formação especializada pelas instituições culturais - escolas, galerias, museus - prevalece o autodidatismo e a reinterpretação da ambiguidade da arte joalheria. Portanto, o que predomina no entendimento de um trabalho de arte é a de comunicar e expressar questões pessoais do artista. 


\section{Seguindo a Joalheria Contemporânea}

O intuito, ao entrevistar produtores do segmento da joalheria contemporânea, observar o coletivo dos artistas joalheiros mexicanos, assim como, acompanhar as atividades de um simpósio de joalheria desse segmento foi o de conhecer, a partir de suas práticas, a maneira como realizam seus projetos, como se reconhecem e se autodenominam. Vale ressaltar que a ideia deste estudo não é a de encontrar um modelo único de atuação, mas seguir os próprios atores e, dessa forma, entender suas inovações. Se for correto afirmar que a TAR, como assegura Latour, funcionaria melhor para o que ainda não foi agregada, a teoria pode auxiliar na compreensão desse segmento da joalheria no Brasil e no México, onde as condições de produção da joalheria contemporânea se assemelham.

A experiência no exterior ocorreu de forma distinta do que foi realizado com os joalheiros contemporâneos brasileiros. Assim, duas fontes diferentes me chamaram atenção para o que estava acontecendo em termos de joalheria contemporânea no México. A primeira fonte foi um repost ${ }^{\mathrm{XX}}$ publicado por uma joalheira inglesa, Jo Pond, no seu perfil do Instagram, em abril de 2014. O post original era de um perfil chamado "the jewellery activist". Esse nome, relacionado a um ativismo na joalheria me chamou muita atenção, de tal modo que, através de uma busca, acabei chegando ao nome de Holinka Escudeiro e de sua rede de comunicação, a qual compreende uma conta no Instagram, uma página no Facebook e um blog <http://holinkaescudero.com/blog/>. Esse é o meio pelo qual Holinka utiliza para apresentar a joalheria contemporânea, tanto o coletivo do qual faz parte, o "Sin Título", quanto os vários eventos relacionados a essa categoria por todo o mundo. Mas como a própria Holinka explica, ela precisava de um nome que se diferenciasse dela mesma, um nome para a comunicação da joalheria contemporâ- nea. E foi a partir dessa busca que surgiu o título "the jewellery activist", o qual dá nome ao site www.thejewelleryactivist.com.

Es lo que te digo: con mi blog, primero estaba conectada con la página de mí trabajo comerciales, entonces el blog era conocido como Holinka Escudero. Después eso no me decía nada, era como Yo, no era eso. Después era ¿o que significa joyería contemporánea? Tampoco me checaba y después de mucho tiempo me concedí el título de "the jewellery activist". Llegó el momento en que me pregunté, ¿ que estoy haciendo? Todo el día, todos los días estoy detrás del monitor viendo joyería, entonces me di cuenta de que la manera en la que me desenvolvía era la manera de un activista. No un activismo heroico, pero la joyería es mí causa y mi convicción. (Entrevistada).

A outra fonte foi um artigo de Kevin Murray ${ }^{x \times 1}$, "Keeping the Faith with Contemporary Jewelry"XXI", no qual ele analisa o surgimentos do coletivo de artistas joaIheiro mexicanos, "Sin Título", e também do coletivo taiwanês, Mano MànMàn. De acordo com o autor, a formação de coletivo foi uma maneira que os joalheiros encontraram para driblar as dificuldades com as quais se deparam, tanto no México, quanto em Taiwan, contextos que diferentemente do Europeu, não encontram espaços de exposição ou colecionadores. Dessa forma, esses atores resolveram se unir para enfrentar tais dificuldades e buscar novas abordagens para atuar na joaIheria de arte. Ou seja, a partir de outras formas de atuação, encontrariam novos caminhos para apresentar a produção na joalheria contemporânea.

Essas duas fontes de informação, que surgiram em um curto espaço de tempo, aguçaram minha curiosidade em conhecer o trabalho dos artistas joalheiros mexicanos. Mesmo antes de ir ao México, 
pude observar, através do artigo de Murray e do blog de Holinka, que o cenário mexicano da joalheria contemporânea tinha muitas semelhanças com o que acontecia no Brasil. De forma que, se a análise de Murray estivesse correta, me interessava conhecer esse trabalho coletivo, que sinalizava para um novo caminho na produção da arte joalheria.

O "Sin Título" estava no processo de implantação do seu primeiro espaço físico, motivo que impediu o meu acesso às suas reuniões. Naquele momento, início de 2015, estavam discutindo questões financeiras relacionadas ao aluguel de uma sala comercial. Entretanto, passado esse primeiro momento, pude acompanhar a reedição dos seus projetos, desta feita, no novo espaço físico do coletivo. No projeto La Chiclera, o funcionamento é exatamente o mesmo do equipamento utilizado para a venda de chicletes; ou seja, nesse caso, eles adotaram uma moeda de 10 pesos mexicanos para ser introduzido na ranhura destinada ao pagamento. Em seguida, giramos a manivela e, de forma aleatória, somos surpreendidos com uma peça dentro de esfera de plástico, que pode ser um colar, anel ou broche. Nesse projeto, ressaltam-se alguns aspectos; o primeiro é a ampliação da concepção corrente do que é joia, já que nele a joia pode ser produzida com diversos materiais, além de poder ser vendida em qualquer lugar, basta transportar o equipamento, prescindindo do espaço específico de uma joalheria. Outro aspecto é a forma de comercialização, já que deslocaram um equipamento comumente usado para vender produtos infantis, doces e chicletes, para a venda de joia, associada ao consumo de luxo, no qual a venda requer um atendimento especial. Ou seja, uma forma de comercialização oposta à venda aleatória proposta no "La Chiclera". Nesse sentido, o trabalho tinha a intenção de ampliar o público consumidor de joalheria contemporânea, na medida em que oferece um produto com um preço popular ${ }^{\mathrm{XXII}}$ e, ao mesmo tempo, apresenta e divulga, através de uma proposta lúdica, o segmento da joalheria contemporânea.

O outro projeto, San Titulo, faz um jogo com a palavra San, santo em espanhol, e o nome do coletivo, "Sin Titulo". A ideia do trabalho teve como origem a dificuldade que os joalheiros precisam enfrentam a fim de realizar seus trabalhos. Como a sociedade mexicana vive sob uma forte tradição do catolicismo, onde há santos para todas as causas, o coletivo decidiu que também precisavam criar o santo do joalheiro contemporâneo. Ao santo, os membros do coletivo pedem que ele forneça fé na disciplina e força para continuarem o trabalho como joalheiros. Neste caso, eles chamam atenção para a necessidade da fé para lograr atuar como joalheiros contemporâneos, uma vez que para conseguir ultrapassar todos os obstáculos de formação, exposição e comercialização com os quais se deparam, necessitam contar com a força de um santo. Nas palavras de Alberto, um dos membros do coletivo, "En México, dedicarse a la joyería contemporánea es un ato de fé". Esse trabalho gerou um vídeo, o qual foi apresentado no simpósio de joalheria contemporânea, "En Construcción II"XXIV, em setembro de 2015.

Em algumas das ações que pude acompanhar do "Sin Título", havia uma nítida preocupação em formar público e posicionar a joalheria contemporânea, através da diferenciação com os outros segmentos da joalheria. Em um desses encontros, o grupo convidou a professora Daniela Rivera para realizar uma palestra sobre sua experiência em joalheria contemporânea. A ideia do coletivo, ao promover esses eventos, é apresentar e divulgar o próprio segmento de joalheria contemporânea. Para isso, pretendiam formar uma agenda de eventos para movimentar o Estúdio Sin Título, sendo as palestras um importante momento de discussão e de formação de público. 
Holinka enfatiza a importância que os dois simpósios, "Walking in the gray área" (2010) e "En Construcción" (2012) tiveram para definir o segmento da joalheria contemporânea para eles, que estavam no México, e que conheciam essa abordagem da joalheria por livros e pela internet. A possibilidade de reunir, trocar e conectar com pessoas interessadas na mesma atividade foi decisivo para promover o surgimento do coletivo de artistas joalheiros mexicanos.

A partir destes relatos podemos observar a importância que os Simpósios operaram para o surgimento de uma associação em torno da joalheria contemporânea. Como no México não se encontram as instâncias de formação profissional, onde as pessoas interessadas por essa atividade possam discutir as questões relacionadas ao segmento, os Simpósios foram responsáveis por promover a descoberta da joalheria de arte.

Nesse sentido, a associação é performativa os integrantes do "Sin Titulo" deram início e se reconhecem como grupo na medida em que formaram o coletivo a fim de encontrar um objetivo que reunisse pessoas em torno de uma atividade que tem a joia como resultado de uma expressão artística. A definição do coletivo também é performativa, já que nela se encontra um esforço por sua manutenção, assim como por demarcar suas diferenças com as outras formas de atuar em joalheria. Esse aspecto de luta por se apresentar e constituir um segmento profissional é também denominado de ativismo por Holinka. De acordo com Latour (2012), o mundo social só pode ser captado quando ocorre alguma mudança, por mais sutil que seja, na qual se opera uma diferença com uma associação mais antiga. Nesse sentido, esse movimento contínuo e performativo do ativismo praticado pelo "Sin Titulo", implica em precisar ser representado constantemente a fim de definir a joalheria contemporânea.

\section{Considerações Finais}

Ao reconstruir as diferentes posições da Joalheria, levando em consideração tendências que vem do mercado e tendências que vem do campo da arte, a fim de ver como tudo isso se articula, objetivou-se localizar as diversas categorias que compõem a estrutura interna deste campo profissional.

Identificou-se uma série de aspectos que impactam na atuação do joalheiro contemporâneo, pois, como inexistem algumas instâncias para a atuação no segmento, a saber: escolas de formação, pontos para comercialização e colecionadores, a solução que esses profissionais encontram para garantir o sustento e permanecer atuantes na categoria consiste no desempenho de outras atividades dentro e fora do campo. Os trabalhos alternativos identificados variaram bastante; no México, como o coletivo era formado quase exclusivamente por designers, com exceção da Zina, que era restauradora de formação e intercalava a restauração com a joalheria, os trabalhos alternavam entre designers de indústria, como Brenda Farías, que trabalha para a indústria moveleira, enquanto outros atuam como designers de marca comercial de joalheria, ou como docentes. Ainda do México, Holinka se responsabiliza por um blog, cujo foco da ação reside em comunicar e divulgar a joalheria contemporânea. Portanto, além da atuação no coletivo "Sin Título", todos possuem uma fonte de renda em outras atividades. O mesmo ocorria com os joalheiros contemporâneos brasileiros, ou seja, verificou-se a dificuldade em atuar exclusivamente na própria categoria, conduzindo-os a trabalhar em outras áreas, inclusive em trabalhos temporários ou por projetos e/ou ainda serem financiados pela família, compreendido no sentido de um alargamento da permanecia na casa dos pais ou através do suporte de um cônjuge que os permitem trabalhar no que gostam. 
Conclui-se, portanto, que a atuação na joalheria contemporânea está condicionada às limitações da pouca visibilidade e reconhecimento, intrínsecas a esse segmento, impondo aos seus produtores a precariedade das práticas laborais.

Nesse ponto, vale lembrar as observações contidas no artigo do Murray (2014), as quais despertaram minha curiosidade e motivaram o meu interesse pelo coletivo de artistas joalheiros mexicanos. Em seu artigo, o autor aponta que a atuação do coletivo "Sin Título" fora uma forma de driblar as condições desfavoráveis com as quais os atores se deparavam no México, onde, diferentemente do contexto da Europa, não encontravam espaços expositivos ou colecionadores. Contudo, ao contrário desse argumento, o que se observou nas performances desses atores foi o ativismo social, o empenho em difundir e desenvolver a joalheria contemporânea no México. O sentido aqui empregado para ativismo refere-se aos novos modos de engajamentos político, conduzindo a ação dos joalheiros contemporâneos no esforço em constituir uma categoria. Para isso, promovem eventos, palestras, convidam outros membros como porta-vozes para darem seus depoimentos e, dessa forma, auxiliarem na construção da categoria. Quer dizer, o coletivo de joalheiros mexicano sabe que o público interessado pela joalheria de arte é muito reduzido, por isso, elegeram como foco de ação, essa forma de ativismo objetivando expandir sua comunicação a mais pessoas, para, aí sim, poder criar condições de atuação. Portanto, nesse momento, a luta é centrada em instituir a categoria.

\section{Bibliografia}

ARCHER, Michael. Arte contemporânea: uma historia concisa. São Paulo: Martins Fontes, 2001.

BELTING, Hans. O fim da história da arte: uma revisão dez anos depois. São Paulo: Cosac Naify. 2006.
BESTEN, Liesbeth den. On Jewellery - a compendium of international contemporary art jewellery. Stuttgart: Arnoldsche Art Publishers, 2011.

CANCLINI, Nestor García. Introdución. De la cultura postindustrial a las estratégias de los jóvenes. In: CANCLINI, Nestor García; CRUCES, F.; POZO, M. U. C. (coords.). Jóvenes, culturas urbanas y redes digitales. Barcelona: Editora Ariel, 2012. p. 3-24.

DANTO, Arthur C. Após o fim da arte: a arte contemporânea e os limites da história. São Paulo: Odysseus Editora/Edusp, 2006.

LATOUR, Bruno. A Dialog on Actor Network Theory. In: AVGEROU, C.; CIBORRA, C.; LAND, F. F. (eds.). The Social Study of Information and Communication Study. Oxford University Press,2004. p.62-76. Disponível em: http://www.bruno-latour.fr/sites/default/ files/90-ANT-DIALOG-LSE-GB.pdf. 2004a.

LATOUR, Bruno. A esperança de Pandora: Ensaios sobre a realidade dos estudos científicos. Bauru, SP: EDUSC, 2001.

LATOUR, Bruno. Jamais fomos modernos: ensaio de antropologia simétrica. Rio de Janeiro: Editora 34, 1994.

LATOUR, Bruno. Por uma antropologia do centro [entrevista]. Mana, v. 10, n. 2, Rio de Janeiro, outubro de 2004(b).

LATOUR, Bruno. Reagregando o social: uma introdução à teoria do ator rede. Salvador: Edufba, 2012.

MURRAY, Kevin. Keeping the Faith with Contemporary Jewelry: The Rise of the Collective in Mexico, Taiwan and Beyond. Art Jewelry Forum, San Francisco, 22 nov 2014. Disponível em http://www. artjewelryforum.org. Acesso em 30 nov. 2014.

ROJAS, Jorge. Ramón Puig Cuyás: la armonía matemática. In: GOLD AND TIME. Diario online de información sobre joyería y relojería. Noticias y actualidad del sector de la joyería y la relojería. Disponível em: http://www.goldandtime.org/noticia/80898/ Goldtime/La-armonia-matematica-de-Ramon-Puig-Cuyas.html. Acesso em 29 Jan. 2016.

SKINNER, Damian. A Künzli for Our Time? Art Jewelry Forum, San Francisco,. 21 mai 2013. Disponivel em: <http://www.artjewelryforum.org/ print/2912>. Acesso em 27 mar. 2015.

TURNER, Victor W. O processo ritual: estrutura e anti-estrutura. Petrópolis, RJ: Vozes, 1974. 
VIDELA, Ana Neuza Botelho. Joalheria, arte ou design? Recife: Universidade Federal de Pernambuco, 2016. Tese de Doutorado em Design.

\section{Recebido em 18/10/2016 Aprovado em 05/11/2016}

I Ana Neuza Botelho Videla. Doutora em Design pela Universidade Federal de Pernambuco. Coordenadora do curso de Design do Produto da Universidade Federal do Cariri, Brasil. Contato:

\section{VER: https://artjewelryforum.org/}

III O termo coletivo nesta pesquisa é usado em dois sentidos. O primeiro, que é o adotado neste parágrafo, é a denominação dos grupos que reúnem artistas para o desenvolvimento de obras em conjunto. O outro é derivado do sentido latouriano do termo, o qual significa as redes compostas por atores humanos e não-humanos.

IV Entrevista com um grupo de joalheiros realizada em 14 junho de 2014.

V Tissa comentou que a formação contava com aulas práticas de ourivesaria e teóricas de química, história da arte, economia, política, matemática e gemologia.

VI A qualidade a que se refere é da precisão e ajustes das ferramentas suíças e alemãs.

VII Ramón Puig Cuyas é professor de joalheria na Escola Massana, em Barcelona. A escola faz parte do centro municipal de arte e design, tendo sido fundada em 1929. Ramon possui uma carreira exitosa na joalheria contemporânea e de reconhecimento internacional, desde 1974, seu trabalho tem sido exposto em várias cidades da Europa, Estados Unidos e Canadá.

VER: http://www.escolamassana.es/es/page.asp?id=21

VIII Depoimento de Ramón Puig Cuyás Ver: http://www. goldandtime.org/noticia/80898/Goldtime/La- ${ }^{\circ}$-armonia${ }^{\circ}$ C)-matematica- ${ }^{\circ}$ C)-del- ${ }^{\circ}$ (C)-joyero- ${ }^{\circ}$ (C)-Ramon- ${ }^{\circ}$ ㅇ-Puig${ }^{\circ}$ C)-Cuyas.html

IX O sentido de gemas é derivado da gemologia, significa pedras preciosas.

$X$ Essas informações fazem parte da minha própria trajetória profissional.

XI Entrevista concedida por Lívia Canuto em 20 Maio 2014.
XII Rudolf Ruthner é natural de Viena, Áustria, de 1941. Em 1966, se formou em mestre de ourivesaria e prataria e complementou sua formação através da trabalho desenvolvido em vários ateliês, tanto em Viena, como em Munique. Mora no Brasil desde 1974.

XIII Rudolf Ruthner, encontro com joalheiros em 14 de Junho de 2014.

XIV Por "experimentação" entende-se uma atuação que rompe com as convenções e desafia as tradições do campo.

XV Francisca Kweitel é joalheira artista argentina e fez formação de joalheria contemporânea na Escola Massana, em Barcelona. Se reconhece como gestora e já realizou vários eventos de joalheria, o mais recente foi o Simpósio "En Construcción II", que ocorreu entre 1 a 5 de Setembro de 2015, em Valparaíso, Chile.

XVI Ver: http://www.liesbetbussche.com/urban_jitc.html

XVII Conheci Gemma Draper devido a sua participação no Simpósio "En Construcción II", em setembro de 2015. Foi nesse evento que assisti a sua palestra, na qual apresentou o trabalho que desenvolveu na residência artística na Inglaterra, além de ter aproveitado para conhecer seu posicionamento sobre a joalheria contemporânea.

XVIII Francisca Kweitel, entrevista concedida em 9 Setembro 2015, em Buenos Aires.

XIX Coletivo de artistas joalheiros mexicanos.

XX O repost é uma ferramenta que permite, ao usuário da rede social instagram, repassar um conteúdo de sua comunidade, mantendo a autoria original da quem postou a mensagem.

XXI Kevin Murray escreve artigos para o site http://www. artjewelryforum.org/. Ele é curador e escritor residente em Melbourne. Com Damian Skinner escreveu "Place \& Adornment: a history of contemporary jewellery in Australia and New Zealand (Bateman Publishing, 2014).

XXII Ver: https://artjewelryforum.org/articles-series/keeping-the-faith-with-contemporary-je

XXIII Na época, em 2015, o cambio de dez pesos mexicanos tinha o valor em torno de $\mathrm{R} \$ 2,00$.

XXIV Ver: http://holinkaescudero.com/blog/category/ sin-titulo/ 